\title{
A Spatial-Temporal Analysis of Cultural and Creative Industries with Micro-Geographic Disaggregation
}

\author{
Iván Boal-San Miguel(D) and Luis César Herrero-Prieto *(i) \\ Research Group on Cultural Economics, Department of Applied Economics, Faculty of Commerce, \\ University of Valladolid, 47011 Valladolid, Spain; ivan.boal@uva.es \\ * Correspondence: herrero@emp.uva.es
}

Received: 13 July 2020; Accepted: 6 August 2020; Published: 7 August 2020

\begin{abstract}
Recent years have witnessed growing interest in studying the spatial distribution of cultural and creative industries (CCI), both for their contribution to economic development and for their impact on spatial planning and remodeling of urban structure. However, spatial interdependence and diffusion of agglomeration economies have not been explained enough so far, due to the use of aggregate spatial units. This paper examines CCI sector location patterns in Spain from a spatial-temporal perspective, using micro-geographic data and considering a new and hitherto unused territorial unit, districts, an intermediate demarcation between municipalities and provinces or regions. We used a geographic information system (GIS) analysis and spatial econometric techniques to study territorial distribution and spatial dependences. Results show that CCI are mainly concentrated in metropolitan areas, with spillover effects in adjacent districts, reflecting a non-contemporary spatial dependence process, whilst large territories are devoid of these effects. This reveals a new source of regional disparities, as CCI seems to follow technology gap models, triggering greater and more intense spatial imbalances wherever it appears. Policy implications regarding accountability resources and institutional coordination must be deduced.
\end{abstract}

Keywords: cultural and creative clusters; dynamic spatial analysis; agglomeration economies; micro-territorial analysis

\section{Introduction}

The cultural and creative industries (CCI) sector is an area of economic activity whose principal purpose is the production or reproduction, promotion, distribution, and/or commercialization of goods, services, and activities of a cultural, artistic, or heritage-related nature [1]. This sector has generated increasing attention in academic, public, and political discourse in recent decades. The first reason is that this sector currently plays a key role in regional economic growth, not only because of the increasing economic flows it generates in terms of income, employment, and activities [2,3], but also because it offers production diversification for certain regions and enclaves and can strengthen new territorial competitiveness profiles. Furthermore, because cultural and creative activities manage talent and technological knowledge, they are associated with innovation strategies and new productive entrepreneurship [4], which reinforces territorial competitiveness. It also seems that higher levels of cultural activity in a region, on both the supply and demand side of cultural goods, are linked to greater regional economic resilience, at least when measured by the ability to curb job losses [5]. The development of CCI also affords an opportunity for urban regeneration, as the urban environment offers a high quality setting, which proves stimulating, motivating, challenging, and inspiring for creative people, such that cultural and creative activities are, spatially speaking, highly concentrated in each country's major cities [6,7]. In this vein, the creative economy has also become an important instrument in regenerating cities, contributing to a revised spatial model of urban structure, and helping 
in the redevelopment of old areas of towns, especially in old industrial districts with abundant industrial heritage [8]. The development of the CCI sector also contributes to designing a new image and competitive profile of enclaves in the line of smart cities and creative cities $[9,10]$. Finally, some studies also point to the possibility of a certain dissemination process of the CCI sector to less-urbanized and rural territories due to the spatial independence of many of these activities that are associated with talent or creation. These can therefore migrate to less crowded areas that offer a higher quality of life [11]. However, the ultimate effect to emerge thus far seems to show that centripetal forces towards concentration are higher than diffusion effects in the territory [12].

In all these processes, the sticky element is the territory itself, a place where agents interact and where proximity and access to specialized labor markets, communication infrastructures, and amenities, as well as a favorable institutional environment and an open society background, seem to be determining factors of agglomeration economies in the CCI sector [13,14]. The question to be asked concerns whether CCI clusters in the main urban structures have grown over time due to spatial externalities, and whether peripheral areas might have benefited from this growth due to the spread of spatial spillovers, in sum, whether or not significant decentralization and urban decongestion effects might be considered to exist.

Based on these considerations, this work aims to analyze structure, dynamics, and agglomeration economies in the CCI sector in Spain as a case study, adopting a spatial-temporal approach, drawing on business activity data at a micro-geographical disaggregation level. We aim to offer a three-fold contribution to the scientific literature exploring CCI. First, in order to measure the scope of agglomeration economies and to identify cultural and creative spatial clusters, we used a new spatial scale, the district, which lies between local units and regions and provinces, and which allows us to consider spatial processes in sufficient territorial detail, without the difficulties faced when dealing with databases at the municipal scale. This spatial unit of analysis has hitherto scarcely been used in this line of research. Second, we studied location patterns of the CCI sector in an effort to ascertain concentration processes in the territory or possible spatial diffusion effects. We used geographic information system (GIS) mapping and statistical tools for this purpose. Finally, we analyzed spatial dependence, both for the CCI sector as a whole as well as for the specific constituent subsectors, in order to pinpoint territorial clusters from a spatial-temporal econometric analysis perspective.

We consider the Spanish CCI sector between 2007 and 2017 as a case study, a long period of time that includes stages of recession and economic expansion. We use data on business activity from companies in Spain that are listed in the Mercantile Register, taking into account the creation and closure of firms, which also enables us to study the sector's demographic dynamics. It is worth noting that most studies on this topic tend to consider the aggregate sector as a whole and for a specific moment in time, using data on employment and applying regional and provincial levels as the spatial unit. The present research is motivated by the conspicuous lack of studies that offer a disaggregated approach for the various sectors of CCI from a spatial-temporal perspective, as well as the use of a high level of spatial disaggregation, which enables more detailed identification of the scale of agglomeration economies and therefore allows inferential spatial analyses to be carried out.

The study is divided into five sections. Following on from this introductory part, Section 2 provides a summary of the theoretical analysis of CCI agglomeration economies, and offers a review of the studies carried out in this regard; Section 3 presents the research's methodological approach and the delimitation of the case study; Section 4 analyses the results to emerge from the empirical application. Finally, Section 5 presents the main conclusions and policy implications.

\section{Delimiting the CCI Sector and Studying Agglomeration Economies: A New Perspective from Smaller Spatial Units}

The importance and recognition of the cultural and creative industries sector emerged as a result of the Creative Nation: Commonwealth Cultural Policy [15] report in Australia, and subsequently became popular after the British government's Department of Culture Media and Sports [16] publication and 
the Creative Industries Mapping Document $[17,18]$, which provide an inventory sectorial approach to recognizing these types of activities. The term "creative industry" was also reflected by KEA [19], with the United Nations Creative Reports $[20,21]$ becoming a common reference. Today, there is still no final consensus concerning which activities are included in the field, as defining and delimiting the CCI sector remains a daunting and widely debated challenge. Numerous studies have sought to limit the identification of this kind of activity for operational purposes, and achieving a consensus in this regard has proved a complex task given the disparate availability of statistical data depending on countries, the specific moment, and the units of spatial analysis employed. As a starting point, we may define creative industries as those that are grounded in creativity, in other words, a combination of skill, individual talent, and market opportunity, displaying great potential for the creation of wealth and employment related to generating and exploiting intellectual property. In this regard, reports on the creative industries issued by the UNCTAD $[20,21]$ have become a common conceptual reference, as they standardize the criteria for defining the sector and establish a conceptualization of creative industries. Based on this notion, creative ideas originate at the nucleus of the creative arts (music, literature, and fine arts), with these ideas and influences becoming increasingly diffuse as they move away from the center through a series of layers or concentric circles. The resulting cultural and creative products thus gradually shed their purely artistic purpose (art for art's sake) and become goods and services that are reproducible in nature and market-oriented, and in which creativity is rewarded, primarily in the form of property rights in the cultural industries sector or through payments for prototypes in the creative industries sector, and which ultimately focus on market demand.

Based on this theoretical framework, we take an operational definition for research into the cultural and creative activities sector in Spain, our case study, which is therefore divided into three main blocks, whose specific composition is shown in Table 1, and which we now detail. This definition is fairly similar in structure and composition to that chosen in other studies on the territorial characterization of the CCI sector, both in Spain [22] and in Europe [23]. First, we have the so-called central nucleus of the arts and heritage, which refers to activities linked to the purest artistic creations, which are individual and occasionally irreproducible, and which have an eminently cultural focus. This nucleus contains the plastic arts and performing arts as well as management of performances, literary creation, and cultural education, together with activities linked to cultural heritage resources-historical ensembles, archaeological sites, as well as museums, archives, and libraries. Secondly, we group activities related to cultural creations that are reproducible in nature and depend on the market, although they also generally imply copyright services stemming from the author's intellectual property. We are therefore talking about the cultural industries in their most basic designation, which refer to the publishing sector and the book industry, reproduction of recorded mediums (video and music), and the film industry (production, distribution, and screening), as well as activities related to communication, television, radio, and press. Finally, there is the group of creative industries where culture and knowledge become the input required for creation, but where the focus is purely on the market, in other words, catering to or triggering a new niche for demand, where payment comes not so much from reproduction rights but from payment for the uniqueness and creative component involved in production. This group comprises activities such as crafts, fashion design, jewelry and toys, the manufacture of musical instruments, the publication of computer programs and video games, as well as creative services such as architecture, advertising, experimental research together with development, and other related activities.

Agglomeration economies refers to the spatial concentration of economic activity, as businesses are not located in a uniform manner over an area, but tend to be concentrated in certain areas, taking advantage of the benefits afforded by proximity and interaction. The influence of agglomeration economies on business location has been the subject of inquiry for decades, although the issue has come into particular focus in recent years, with works emerging that take advantage of the ever-increasing availability of micro-geographical data and geographical information systems $[25,26]$, which allow for the study of business location patterns based on new units of spatial analysis. At this territorial level, 
certain determining effects of agglomeration, such as the concentration of human capital, the provision of infrastructures, or the effect of amenities, can be better appreciated [27].

Table 1. Activities in the cultural and creative industries (CCI) sector.

\begin{tabular}{|c|c|c|}
\hline Industries & Activities & Activity Codes NACE Rev.2 \\
\hline $\begin{array}{l}\text { Cultural heritage } \\
\text { Performing arts } \\
\text { Artistic and literary creation } \\
\text { Cultural education } \\
\text { Photography }\end{array}$ & $\begin{array}{l}\text { 1. Central nucleus of arts and cultural heritage } \\
\text { Museums, libraries, archives, leisure and entertainment } \\
\text { Performing arts and theatre halls management } \\
\text { Sculptors, cartoonists, writers, restorers } \\
\text { Education activities for arts, theatre and dance } \\
\text { Photographic activities }\end{array}$ & $\begin{array}{c}7990 ; 9101 ; 9102 ; 9103 ; 9104 ; 9321 ; 9329 \\
\text { 9001; } 9002 ; 9004 ; \\
9003 \\
8552 \\
7420\end{array}$ \\
\hline $\begin{array}{l}\text { Cinema, video and music } \\
\text { Radio and television } \\
\text { Publishing and editing }\end{array}$ & $\begin{array}{c}\text { 2. Cultural industries } \\
\text { Film, video, television, sound recording and editing activities } \\
\text { Broadcasting and programming activities } \\
\text { Printing, graphic arts, multimedia, and other } \\
\text { editorial activities }\end{array}$ & $\begin{aligned} 1820 ; 5911 ; 5912 ; 5913 ; 5914 ; 5920 \\
6010 ; 6020 \\
1811 ; 1812 ; 1813 ; 1814 ; 5811 ; 5813 \\
5814 ; 5819\end{aligned}$ \\
\hline Crafts & $\begin{array}{l}\text { 3. Creative industries } \\
\text { Manufacture of musical instruments, jewellery, coins and other } \\
\text { related activities }\end{array}$ & $\begin{array}{c}2899 ; 3211 ; 3212 ; 3220 ; 3240 ; 3319 ; \\
3320 ; 9529\end{array}$ \\
\hline Software and videogames & $\begin{array}{l}\text { Videogame edition, computer programs, web edition and } \\
\text { computer consulting activities }\end{array}$ & $5821 ; 5829 ; 6201 ; 6202 ; 6209$ \\
\hline Research and development & $\begin{array}{l}\text { Research and development in biotechnology, natural and } \\
\text { social sciences and humanities activities }\end{array}$ & $7211 ; 7219 ; 7220$ \\
\hline Architecture and engineering & Architecture, topography and engineering activities & $7111 ; 7112 ; 7490$ \\
\hline Advertising & Advertising, marketing and representation services agencies & $7311 ; 7312$ \\
\hline Fashion and related activities & Textile and fashion design activities & $\begin{array}{c}1320 ; 1412 ; 1413 ; 1414 ; 1419 ; 1431 ; \\
1520 ; 3299\end{array}$ \\
\hline
\end{tabular}

Source: Author's own based on UNCTAD [21] and Boix et al. [24].

Agglomeration economies in the CCI sector have also been the subject of study, where economies of location (business concentration) and urbanization (territorial agglomeration) are not mutually exclusive but are indeed more complementary [28]. The production of cultural and creative goods and services is characterized by the use of talent and innovation, which involve aspects related to intellectual property, and which convey a symbolic meaning. From a general perspective, the most knowledge-intensive activities tend to be located in areas with high economies of location, whereas more traditional activities tend to be distributed in a more disperse manner [29]. Nevertheless, insofar as creative activities imply the transformation of talent and the use of the innovative skills of workers and entrepreneurs, they demand constant social interaction as well as spatial interaction [30], which provides the advantage of economies of urbanization for these activities [14,31]. Here we also find the creative class thesis [32], which conjectures as to the concentration of the so-called creative classes in specific areas that provide the conditions for accumulation of talent, a tolerant environment, and access to technology. Andersson et al. [33] also underpin the importance of interaction among artists when accounting for their locational preferences in specific areas. Proximity seems to be a key aspect for the agglomeration of cultural and creative enterprises, as it generates important benefits linked to the concentration and density of exchange between cultural and creative agents [34,35].

As a result of these considerations, numerous authors have broadened the notion of industrial district to new sectors such as CCI, leading to an extension of the Marshallian notion to the concept of cultural and creative district [36,37]. The intensification of the spatial link between creative industries shifts the focus to the role played by territory in CCI location decisions. A creative cluster [38] can therefore be defined as an agglomeration of businesses involved in creative activities in a specific area that compete and cooperate, maintaining market relations with one another. $\mathrm{CCI}$ tend to converge towards spatial clusters as an organizational structure, where each production unit encompasses a wide system of socioeconomic interactions on which, to a certain extent, their life-cycle in the market depends. Moreover, spatial distribution of $\mathrm{CCI}$ is closely related to economic disparities and the degree of spatial economic development. Imbalances are even stronger, as regional creative potential seems to follow technological gap models, which give rise to an asymmetric distribution with more intense spatial concentration whenever and wherever it appears [7], such that peripheral regions scarcely benefit from the expansion of CCI [12]. 
Existing empirical evidence shows the importance of agglomeration economies in the CCI sector, whose geographical distribution ultimately tends towards a concentration in certain locations. This locational pattern has been evidenced in a number of cases such as the United States [39], Europe [22,23,36,40], and Asia [41]. A thorough review of the literature on agglomeration economies in the cultural and creative sector can be found in Gong and Hassink [28]. For Spain, several works can also be found, such as Boix and Lazzeretti [22], who identify creative clusters through employment data, using local production systems as a spatial unit. Casares et al. [42] analyze the distribution of the creative classes and their contribution to economic growth at a provincial disaggregation level. Méndez and Sánchez Moral [43] examine the geography of CCI for all towns of over 20,000 inhabitants, while Escalona et al. [11] focus on smaller demographic strata and rural areas. Finally, Méndez et al. [44] and Coll-Martínez et al. [45] take micro-spatial analysis as a reference to study the agglomeration of creative industries in Spanish urban areas and the metropolitan area of Barcelona, respectively. This research aims to provide further insights into and to contribute towards current knowledge on the location and distribution of CCI in Spain from a new spatial-temporal perspective using econometric tools and adopting a hitherto unused micro-spatial demarcation, namely districts.

\section{Case Study and Methodology}

Our research goal was to study the structure, dynamics, and behavior of agglomeration economies in the CCI sector, adopting a new spatial-temporal perspective and using a new micro-spatial unit, districts. This enabled us to answer a number of questions: Is the spatial analysis unit used important in the results obtained? Are there dynamic agglomeration economies in the CCI sector, with dissemination and spatial spillover effects over time? Do all CCI sectors behave similarly? Is there spatial-temporal dependency? Do the spatial patterns between the various subsectors that make up the CCI differ? Our research aims to provide an answer to these questions, and in this section we describe the method proposed to achieve our goals, which includes the use of a new spatial scale as well as various spatial econometric techniques, adopting a spatial-temporal approach.

\subsection{Data Sources and Spatial Units for Analysis}

As regards spatial demarcation for the analysis of CCI, it is worth noting that most studies use provincial or regional administrative divisions, but that few works focus on the local level, at least in Spain, given the difficulty of creating a database with this level of disaggregation for the country as a whole. As already pointed out, the interest in these studies with micro-spatial disaggregation lies in the possibility of comparing locational and territorial decentralization processes in greater detail. Nevertheless, they have the drawback that they are on occasions excessively restrictive units, and it seems reasonable to assume that economic processes stretch beyond said areas and have an impact on wider neighboring units. There is also the limitation concerning reliability when gathering data in such small units as municipalities and the problems in the inferential calculation we implement due to the excessive presence of zeros in the database. As a result, our operational proposal for the analysis involved considering a geographical area that lies between the municipality and the province, namely the district, and which therefore allows for territorial analysis at an important level of disaggregation that is able to pinpoint micro-spatial processes whilst also maintaining the conditions of contiguity over the area. Such an administrative demarcation, which has barely been used in spatial economic analysis, is what would correspond at EUROSTAT to the LAU2 denomination (Local Administrative Units), as a sub-provincial territorial (NUTS3) and sub-regional (NUTS2) level, and which represents a functional concentration of municipalities (LAU1). For Spain, starting with an initial network of 8131 municipalities, we therefore took a grouping of 326 districts as the operational territorial unit for the research, with a wider and more disaggregated number of entities compared to the provincial (52) and regional (17) level. Given the lack of a clear definition of this LAU2 institutional level in Spanish legislation, we took agricultural districts as the administrative unit of analysis. We considered these districts simply as a territorial structure, because it is a uniform demarcation that 
appropriately reflects groups of municipalities who share particular social, economic, and territorial singularities. In our case, primary data on information concerning cultural and creative activities corresponded to the lowest possible level of spatial disaggregation (municipal), but grouped into these new geographical units (districts), in an effort to reduce information variability and to facilitate analysis of spatial inference.

As regards variables representing the economic activity of the cultural and creative sector, and following the operational definition of the CCI sector given in Section 2, we used micro-geographic data from SABI (Bureau Van Dijk). This database contains information from Spanish firms, and covers an extremely wide range in spatial and sectorial terms. Data were taken from the Mercantile Register, and contain information on a wide array of variables related to firms, such as the year they were set up and which sector of economic activity they are involved in, in accordance with the NACE Rev.2 classification. Information is also available concerning their precise situation, which allowed the businesses' location to be spatially geo-referenced. The database also provides information regarding the creation and closure of firms, which also enabled us to study the demographic dynamics of CCI. For the purposes of this research, we used the number of firms variable and their location for the period 2007-2017, which enabled a demographic analysis of the sector to be carried out. Other variables of interest vis-à-vis studying the CCI, such as the number of people employed or the sector's aggregate value, were considered, although they presented problems in terms of data availability for the level of micro-spatial disaggregation considered. That is why we focused on businesses' location analysis using number of companies as the main variable. SABI is one of the most widely used sources of data for studies addressing the location of economic activity in Spain, see [24,45]. Some studies have examined the representativeness of this database compared to the Spanish Social Security Register, with the resulting correlation being close to $90 \%$ [29].

\subsection{Spatial Economics Analysis: Methodological Approach}

Two complementary methodological approaches were considered to provide a descriptive and inferential analysis vis-à-vis the processes of CCI agglomeration and offer a study of the temporal trend of their territorial dynamics. As an initial approach, we proposed calculating the Gini concentration index and maps through georeferenced data, using a geographic information system (GIS). Likewise, we employed business dynamics indicators to measure CCI birth and death rates. Second, territorial interactions between neighbors' spatial units were considered by means of spatial econometric analysis, in order to explain location and clustering patterns in the CCI sector. In this way, both methodological approaches allowed us to study the scope of agglomeration economies and the influence of spatial interactions in the territorial dynamic, so as to identify patterns of temporal spatial dependence as well as unusual locations and creative spatial clusters, at micro-geographic firm level.

In the field of spatial econometrics, we used global Moran's I statistic, expressed as follows:

$$
I=\frac{N}{S_{0}} \frac{\sum_{i j}^{N} w_{i j}\left(x_{i}-\bar{x}\right)\left(x_{j}-\bar{x}\right)}{\sum_{i=1}^{N}\left(x_{i}-\bar{x}\right)^{2}} i \neq j
$$

where $x_{i}$ is the value of the variable $x$ in region $I, \bar{x}$ is the simple mean of variable $x, w_{i, j}$ are the components of the spatial weights matrix, $N$ is the sample size, and $S_{0}=\sum_{i=1}^{n} \sum_{j=1}^{n} w_{i j}$.

With regard to the distribution of Moran's I statistic, according to Cliff and Ord [46] the standardized expression of the test is distributed as a normal typified one, and inference is based on the permutation approach with 9999 permutations. The null hypothesis is defined as the likelihood of a region receiving a particular value of a variable being the same for all locations $i$, and is independent of what happens in the rest. In other words, CCI firms are distributed homogeneously in spatial terms. In contrast to the alternative hypothesis, the likelihood is not the same in all regions and/or the observed level of the variable in $i$ is not independent of what happens in the rest. In other words, spatial autocorrelation 
is seen to exist. Interpreting the statistically significant coefficients, non-significant values of $Z_{I}$ lead to the null hypothesis being accepted; significant values of $Z_{I}>0$ are indicative of positive spatial autocorrelation, and significant values of $Z_{I}<0$ are indicative of negative spatial autocorrelation [47].

With a dynamic approach, the spatial-temporal correlation allowed the distribution of CCI at two moments in time to be analyzed, for which the availability of a data panel was necessary (2007-2017). This kind of analysis enabled a study of the phenomena of diffusion and spatial-temporal concentration in order to detect the existence of dynamic agglomeration economies and how they are spread over an area. The spatial-temporal statistic $I_{t}[48]$ is defined as:

$$
I_{t}=Z_{t-k}^{\prime} W_{i j} z_{t} \frac{Z_{t-k}^{\prime} W_{i j} z_{t}}{Z_{t-k}^{\prime} Z_{t-k}}
$$

where $Z_{t}$ and $Z_{t-k}$ are the standardized values of the variable referred to moments $t$ and $(t-k)$, respectively, and $W_{i j}$ the spatial weights matrix. Significant $Z\left(I_{t}\right)$ values are indicative of a spatial-temporal diffusion process, that is, non-contemporary spatial dependence, indicating that spatial interaction not only occurs at a given time, but is present throughout a given period, in other words, a diffusion process across the area.

We used local Moran's I statistic, which disaggregates the result of global Moran's I at the analysis unit level [49]. This indicator enabled us to pinpoint spatial clusters (LISA maps), defined as those locations or set of adjacent locations for which the indicator proves significant, and is defined as:

$$
I_{i}=\frac{z_{i}}{\sum_{i} z_{i}^{2} / N} \sum_{j \in J_{i}} w_{i j} z_{j}
$$

where $z_{i}$ is the value the normalized variable takes in region $i$, and $J_{i}$ the set of areas felt to be neighboring $i$.

As already mentioned, districts are small territorial units with spatial contiguity, which justified the use of this level of disaggregation, and allowed the proposed methodology to be implemented, as the use of spatial techniques required a spatial weights matrix to be estimated. The correct choice of the spatial weights matrix is one of the most difficult and controversial methodological issues in spatial econometrics [49]. For this reason, in the present work the results obtained through two different contiguity matrices, first-order contiguity matrix and inverse distance matrix, have been contrasted, in order to compare both results (in Moreno and Vayá [47] several alternatives can be seen for the definition of a different spatial weights matrix as an instrument for reflecting interdependencies).

\section{Empirical Application}

\subsection{Spatial Structure and Dynamics of CCI}

Table 2 shows the progression of the number of firms in the CCI sector in Spain in the period 2007-2017, classified in subsectors of activities as well as their respective participations over the total number of firms in the economy and the main business demography indicators. In Spain, CCI represent around $12 \%$ of all firms and evidence a growing trend in terms of volume, although the proportion over the total Spanish firms remained almost the same. The growth in the number of firms involved in CCI during the period analyzed was $35.7 \%$, with an annual growth rate of $3.10 \%$, with the specific sector of the creative industries evidencing the highest annual growth rate, reaching 3.25\%, whilst firms in the arts and cultural heritage sector and the cultural industries sector achieved rates of $2.95 \%$ and $2.58 \%$, respectively. 
Table 2. CCI dynamics in Spain.

\begin{tabular}{|c|c|c|c|c|c|c|c|c|c|c|}
\hline $\begin{array}{l}\text { Activity } \\
\text { Sector }\end{array}$ & Year & $\begin{array}{l}\text { No. of } \\
\text { Firms }\end{array}$ & $\begin{array}{c}\text { Percentage over } \\
\text { Total Spanish } \\
\text { Firms }\end{array}$ & $\begin{array}{l}\text { Percentage } \\
\text { over Total } \\
\text { CCI Firms }\end{array}$ & Entries & Exits & GEnR & GExR & $\mathbf{R R}$ & NEnR \\
\hline \multirow{11}{*}{$\begin{array}{l}\text { 1. Central } \\
\text { nucleus of } \\
\text { arts and } \\
\text { cultural } \\
\text { heritage }\end{array}$} & 2007 & 16,197 & 1.63 & 12.96 & 1181 & 124 & 7.29 & 0.77 & 8.06 & 6.53 \\
\hline & 2008 & 17,052 & 1.64 & 12.96 & 952 & 98 & 5.58 & 0.57 & 6.16 & 5.01 \\
\hline & 2009 & 17,705 & 1.65 & 12.93 & 732 & 79 & 4.13 & 0.45 & 4.58 & 3.69 \\
\hline & 2010 & 18,358 & 1.65 & 12.90 & 724 & 71 & 3.94 & 0.39 & 4.33 & 3.56 \\
\hline & 2011 & 18,969 & 1.65 & 12.85 & 671 & 60 & 3.54 & 0.32 & 3.85 & 3.22 \\
\hline & 2012 & 19,590 & 1.65 & 12.80 & 665 & 44 & 3.39 & 0.22 & 3.62 & 3.17 \\
\hline & 2013 & 20,221 & 1.64 & 12.76 & 665 & 34 & 3.29 & 0.17 & 3.46 & 3.12 \\
\hline & 2014 & 20,726 & 1.63 & 12.73 & 525 & 20 & 2.53 & 0.10 & 2.63 & 2.44 \\
\hline & 2015 & 21,161 & 1.61 & 12.74 & 441 & 6 & 2.08 & 0.03 & 2.11 & 2.06 \\
\hline & 2016 & 21,507 & 1.60 & 12.75 & 354 & 7 & 1.65 & 0.03 & 1.68 & 1.61 \\
\hline & 2017 & 21,658 & 1.60 & 12.76 & 150 & 0 & 0.69 & 0.00 & 0.69 & 0.69 \\
\hline \multirow{11}{*}{$\begin{array}{l}\text { 2. Cultural } \\
\text { industries }\end{array}$} & 2007 & 20,354 & 2.05 & 16.28 & 1212 & 182 & 5.95 & 0.89 & 6.85 & 5.06 \\
\hline & 2008 & 21,182 & 2.04 & 16.09 & 946 & 118 & 4.47 & 0.56 & 5.02 & 3.91 \\
\hline & 2009 & 21,866 & 2.04 & 15.97 & 776 & 92 & 3.55 & 0.42 & 3.97 & 3.13 \\
\hline & 2010 & 22,564 & 2.03 & 15.85 & 788 & 90 & 3.49 & 0.40 & 3.89 & 3.09 \\
\hline & 2011 & 23,246 & 2.02 & 15.75 & 741 & 59 & 3.19 & 0.25 & 3.44 & 2.93 \\
\hline & 2012 & 23,905 & 2.01 & 15.62 & 707 & 48 & 2.96 & 0.20 & 3.16 & 2.76 \\
\hline & 2013 & 24,634 & 2.00 & 15.55 & 764 & 35 & 3.10 & 0.14 & 3.24 & 2.96 \\
\hline & 2014 & 25,226 & 1.98 & 15.50 & 611 & 19 & 2.42 & 0.08 & 2.50 & 2.35 \\
\hline & 2015 & 25,703 & 1.96 & 15.47 & 483 & 6 & 1.88 & 0.02 & 1.90 & 1.86 \\
\hline & 2016 & 26,111 & 1.94 & 15.48 & 411 & 3 & 1.57 & 0.01 & 1.59 & 1.56 \\
\hline & 2017 & 26,256 & 1.93 & 15.47 & 146 & 1 & 0.56 & 0.00 & 0.56 & 0.55 \\
\hline \multirow{11}{*}{$\begin{array}{l}\text { 3. Creative } \\
\text { industries }\end{array}$} & 2007 & 88,463 & 8.89 & 70.76 & 7455 & 1160 & 8.43 & 1.31 & 9.74 & 7.12 \\
\hline & 2008 & 93,379 & 8.99 & 70.95 & 5765 & 847 & 6.17 & 0.91 & 7.08 & 5.27 \\
\hline & 2009 & 97,369 & 9.07 & 71.10 & 4578 & 588 & 4.70 & 0.60 & 5.31 & 4.10 \\
\hline & 2010 & 101,435 & 9.13 & 71.25 & 4614 & 548 & 4.55 & 0.54 & 5.09 & 4.01 \\
\hline & 2011 & 105,415 & 9.17 & 71.40 & 4504 & 524 & 4.27 & 0.50 & 4.77 & 3.78 \\
\hline & 2012 & 109,575 & 9.21 & 71.58 & 4556 & 395 & 4.16 & 0.36 & 4.52 & 3.80 \\
\hline & 2013 & 113,558 & 9.21 & 71.68 & 4252 & 269 & 3.74 & 0.24 & 3.98 & 3.51 \\
\hline & 2014 & 116,840 & 9.17 & 71.77 & 3437 & 155 & 2.94 & 0.13 & 3.07 & 2.81 \\
\hline & 2015 & 119,233 & 9.10 & 71.79 & 2445 & 52 & 2.05 & 0.04 & 2.09 & 2.01 \\
\hline & 2016 & 121,078 & 9.02 & 71.77 & 1861 & 16 & 1.54 & 0.01 & 1.55 & 1.52 \\
\hline & 2017 & 121,778 & 8.97 & 71.76 & 700 & 0 & 0.57 & 0.00 & 0.57 & 0.57 \\
\hline \multirow{11}{*}{ Total CCI } & 2007 & 125,014 & 12.57 & - & 9848 & 1466 & 7.88 & 1.17 & 9.05 & 6.70 \\
\hline & 2008 & 131,613 & 12.68 & - & 7663 & 1063 & 5.82 & 0.81 & 6.63 & 5.01 \\
\hline & 2009 & 136,940 & 12.75 & - & 6086 & 759 & 4.44 & 0.55 & 5.00 & 3.89 \\
\hline & 2010 & 142,357 & 12.81 & - & 6126 & 709 & 4.30 & 0.50 & 4.80 & 3.81 \\
\hline & 2011 & 147,630 & 12.84 & - & 5916 & 643 & 4.01 & 0.44 & 4.44 & 3.57 \\
\hline & 2012 & 153,070 & 12.86 & - & 5928 & 487 & 3.87 & 0.32 & 4.19 & 3.55 \\
\hline & 2013 & 158,413 & 12.84 & - & 5681 & 338 & 3.59 & 0.21 & 3.80 & 3.37 \\
\hline & 2014 & 162,792 & 12.77 & - & 4573 & 194 & 2.81 & 0.12 & 2.93 & 2.69 \\
\hline & 2015 & 166,097 & 12.67 & - & 3369 & 64 & 2.03 & 0.04 & 2.07 & 1.99 \\
\hline & 2016 & 168,696 & 12.56 & - & 2626 & 26 & 1.56 & 0.02 & 1.57 & 1.54 \\
\hline & 2017 & 169,692 & 12.50 & - & 996 & 1 & 0.59 & 0.00 & 0.59 & 0.59 \\
\hline
\end{tabular}

Notes: GEnR is the Gross Entry Rate, GExR is the Gross Exit Rate, RR is the Rotation Rate (=GEnR + GExR) and NEnR represents the Net Entry Rate (=GEnR - GExR), rates in percentages.

From an overall sector perspective, it is possible to clearly distinguish various profiles linked to the available data. The greatest proportion of CCI in Spain is made up of creative industries, which represented $71.76 \%$ of the total for the sector in 2017, whilst the cultural industries and arts and heritage sector reached values of $15.47 \%$ and $12.76 \%$, respectively. Moreover, a look at the progression between 2007-2017 of each component's participation out of the total CCI shows that creative industries are the only ones to have increased their weight slightly when compared to the sector as a whole, due to their greater growth rate over this period. These results concur with those obtained by other works that use employment data or GDP [22,44]. In addition, the CCI sector in Spain reflects a creative economy structure similar to that of Italy [23].

A look at the progression of the principal business demography indicators (Table 2) shows how there are no significant differences between the different groups of activity. However, we do see how the group of creative industries evidences the highest gross entry, exit, and rotation rates considering the whole of the period analyzed, followed by the arts and heritage sector. These are the sectors that exhibit the greatest degree of business turbulence, with this being most noticeable during the economic 
crisis (first part of the period considered). In contrast, values for the cultural industries sector are lower, showing that fewer of these businesses were destroyed and therefore reflecting a higher relative survival rate in the market. As a result, the most salient feature of CCI business dynamics is that both the creation as well as the destruction of firms is more noticeable in the classification of the group of creative industries, with turbulence reaching values below $10 \%$ in the rotation rate, with a tendency to fall. These CCI indicators display a similar behavior to that of the service sector in Spain, which evidences rotation rates of between $10 \%$ and $20 \%$, above those of the manufacturing sector $(0-10 \%)$ and lower than those in the construction sector, which exceed 20\% [50].

As regards territorial analysis of CCI, Figure 1 shows the spatial location intensity of these companies taking the district demarcations as the unit of analysis. It should be noted that the size of the dots corresponds to the density of the firms located in each district in each branch. The scale of the map is, therefore, different depending on the scale of each subsector, although an effort has been made to standardize the scale relative to the size of the four maps.

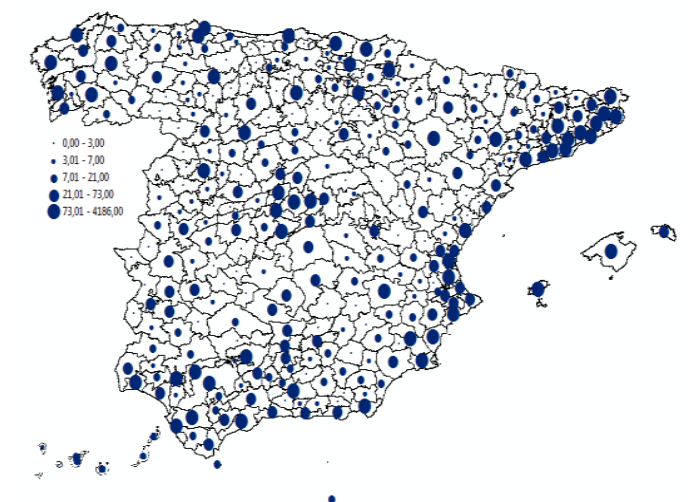

(a)

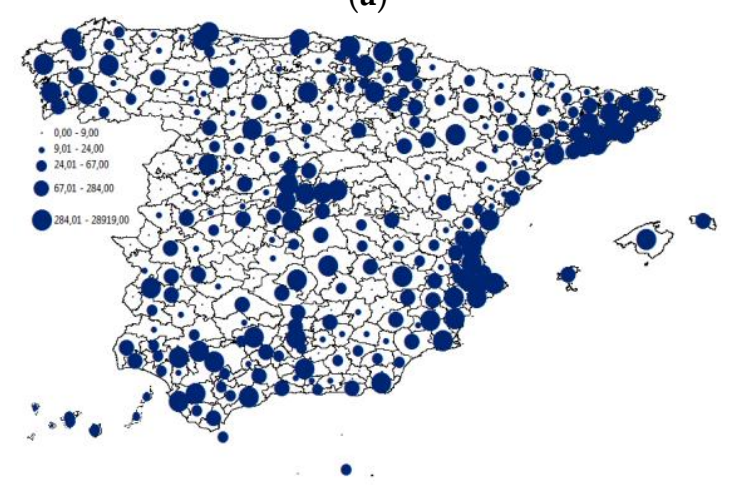

(c)

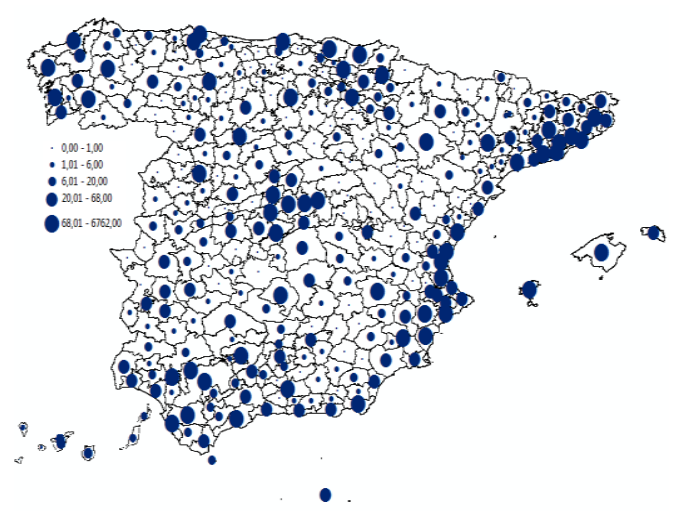

(b)

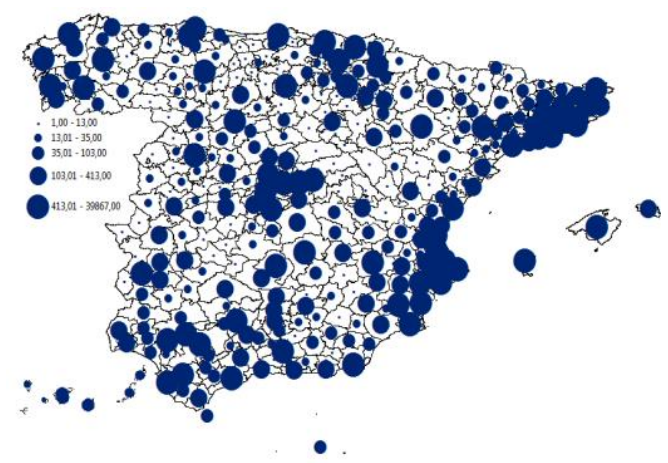

(d)

Figure 1. Location of CCI in Spanish districts in 2017. (a) Central nucleus of arts and cultural heritage. (b) Cultural industries. (c) Creative industries. (d) Total CCI.

Nonetheless, what first emerges as striking when looking at the Figure 1 is the marked concentration of this kind of activity in certain geographical areas in which the advantages stemming from agglomeration economies play a key role. This is the case in the large metropolitan areas of Madrid ( $23 \%$ of firms) and Barcelona (13\%), which emerge as the main poles of attraction and which record concentric extensions towards the neighboring districts, with a greater extension in the case of Cataluña. Another area of location spans the Mediterranean arc between Valencia, Alicante, and Murcia, as well as the nucleus of Basque provinces, which extends towards Navarra and La Rioja. If we add to these areas the poles of Zaragoza in the Ebro valley and Seville and Malaga to the south, overall they can be said to account for over half of the CCI sector in Spain in 2017, in stark contrast to the void apparent in inland regions, particularly in Extremadura and Castilla la Mancha. The location of CCI in Spain 
thus shows major territorial imbalances with a clear concentration in the north east of the peninsula and various large concentrations in certain urban poles in the interior regions and the Atlantic axis in Galicia.

To confirm this concentration, Table 3 shows the distribution of CCI by intervals of frequencies in Spanish districts in 2017. The table reveals how only nine districts account for over half the firms in the sector, corresponding, as expected, to the most urbanized areas, which concentrate $32 \%$ of the country's whole population (these districts are Baix Llobregat and Vallés Occidental (Catalonia), Área Metropolitana (Madrid), Vizcaya (Biscay), Meridional (Alicante), Huerta de Valencia (Valencia), Guadalorce (Malaga), La Vega (Seville), and Zaragoza (Saragossa)). The intermediate areas include 48 districts (15\%) and account for $33 \%$ of cultural and creative firms and $40 \%$ of the population. As pointed out, these are districts adjacent to the large metropolitan areas as well as other secondary urban nodes already mentioned. At the other end of the scale we have the bulk of the rest of the country, $82 \%$ of the districts, which register low location frequencies of cultural and creative activities, accounting for only $13 \%$ of business activity in the sector. The results obtained based on the district level concur with the existing literature in the field. Boix et al. [24] studied the location patterns of creative industries in a comparative analysis to European countries, with the conclusion being that creative industries are more concentrated in Spain than in other countries.

Table 3. Distribution by intervals of CCI in Spanish districts in 2017.

\begin{tabular}{cccccccc}
\hline & \multicolumn{3}{c}{ Absolute Value } & \multicolumn{3}{c}{ Distribution } \\
\hline $\begin{array}{c}\text { Size of Districts by } \\
\text { Number of CCI }\end{array}$ & Districts & CCI & Population & $\begin{array}{c}\text { CCI/1000 } \\
\text { Inhab }\end{array}$ & Districts & CCI & Population \\
\hline$<500$ & 267 & 23,480 & $12,635,738$ & 1.86 & $82.41 \%$ & $13.84 \%$ & $27.15 \%$ \\
$501-1500$ & 34 & 29,411 & $10,041,311$ & 2.93 & $10.49 \%$ & $17.33 \%$ & $21.58 \%$ \\
$1501-3000$ & 14 & 30,738 & $8,986,347$ & 3.42 & $4.32 \%$ & $18.11 \%$ & $19.31 \%$ \\
$3001-40,000$ & 9 & 86,063 & $14,871,765$ & 5.79 & $2.78 \%$ & $50.72 \%$ & $31.96 \%$ \\
\hline Total & 324 & 169,692 & $46,535,161$ & 3.65 & $100.00 \%$ & $100.00 \%$ & $100.00 \%$ \\
\hline
\end{tabular}

In order to chart the progression over time, we took the Gini concentration index (Figure 2) which, for all sectors and throughout the period analyzed, shows major concentration and imbalance in CCI territorial dynamics, again evidencing substantial territorial disparities in the spatial distribution of CCI in Spain. By groups of CCI activities, the location of firms belonging to the nucleus of arts and heritage, which is more closely linked to the existence of endowment resources and cultural institutions, displays an even lower degree of concentration in relative terms, with a slight downward trend. In contrast, the cultural industries and creative activities sectors are more concentrated than the average, with a very similar pattern to that of the sector as a whole. This highlights the greater influence of agglomeration economies in the location decisions taken by these activities.

The concentration indices obtained here reach slightly lower values than the results reported in other works using different spatial units. Using local production systems, Boix and Lazzeretti [22] obtain a Gini index of 0.91 . This concentration pattern for CCI is also noteworthy in the works of García et al. [51] for Spanish regions and Méndez et al. [44] for the Spanish urban system, and for the case of micro-spatial analysis, Boal and Herrero [52] for municipalities in Castilla y León and Coll-Martínez et al. [45] for the metropolitan area of Barcelona. Although all of these studies highlight the importance of agglomeration economies in the distribution of Spanish CCI, it should be pointed out that the spatial unit of analysis may prove to be a key factor when assessing industrial concentration patterns. This question justifies the suitability of using the district delimitation applied in this work, as it enables us to fine-tune the study on the agglomeration economies of CCI and their locational behavior for Spain as a whole, regardless of provincial and regional limits. We can thus more accurately identify the adjacent areas of CCI concentration that make up spatial creative 
clusters. As a result, we consider the analysis of spatial dependence between districts presented below to be relevant.

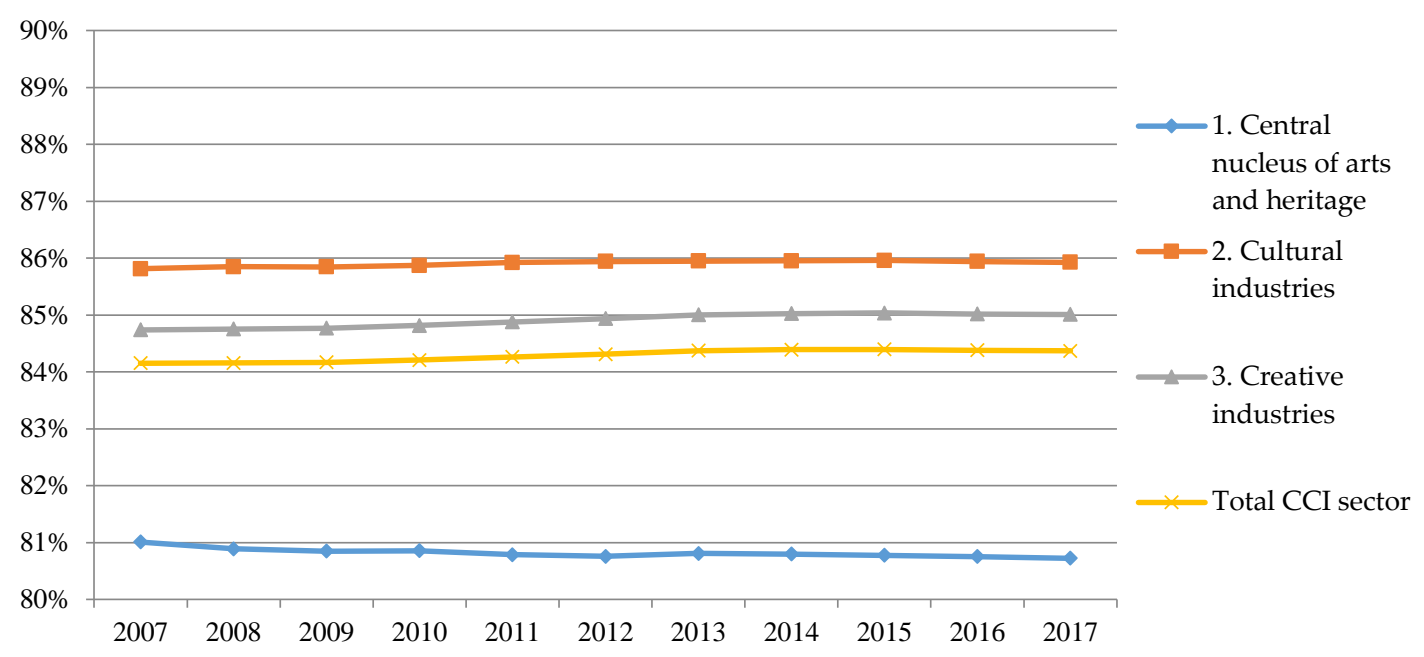

Figure 2. Gini indices. Progression of the spatial concentration of CCI.

\subsection{Spatial-Temporal Analysis of CCI}

This preliminary descriptive analysis shows the CCI agglomeration processes in Spanish districts, taking into account that no interaction between spatial units is considered. This does not permit us to ascertain whether the $\mathrm{CCI}$ in a given district are influenced by the CCI located in neighboring districts, forming what would be termed a spatial locational cluster. Nor did we consider dynamic spatial spillovers. In this vein, global Moran's I statistic allows us to pinpoint the existence of a spatial dependence pattern and its sign. In order to reflect the influence of economies of urbanization, we relativized the variable for the number of firms in per capita terms. This also allowed us to remove possible distortion caused by differences in demographical size and degree of economic development between districts [52].

The Z(I) values obtained for the global Moran's I statistic are shown in Table 4 and evidence positive spatial autocorrelation, with significant $Z(I)$ statistic values at $1 \%$ confidence level. This result allows us to reject the hypothesis of homogeneity, and we can therefore say that the distribution of CCI in Spanish districts displays a deterministic and not a non-random pattern. This confirms that districts exhibit CCI frequencies similar to the participation of their neighboring districts, and that districts with high CCI values and those with low location (high or low) influence each other. This finding implies that $\mathrm{CCI}$ in neighboring districts are correlated with the $\mathrm{CCI}$ in the reference district and tend to group spatially. This triggers spatial spillover effects as well as positive externalities stemming from agglomerative processes. By groups of CCI activities, the subsectors of creative industries and cultural industries achieve higher $Z(I)$ statistic values, followed by firms in the arts and heritage nucleus, as was found for the concentration indices. This means that positive spatial autocorrelation is greater and, therefore, that spatial interaction is stronger in the cultural and creative industries sectors.

In many of the events of an economic nature, spatial dependence between areas is the result of trends that occur due to a spatial-temporal effect [53]. This work explores the structure of the spatial dependence of CCI through a geo-referenced data panel, which allows us to consider dynamic spatial interactions. In this way, the spatial-temporal Moran's $I_{t}$ statistic enables us to evaluate the time evolution of spatial dependence, and provides information concerning the type of spatial dependence, whether instantaneous or contemporary, as well as lagged or non-contemporary. 
Table 4. Global Moran's I statistic for CCI by sectors of activity, 2007-2017.

\begin{tabular}{ccccc}
\hline & $\begin{array}{c}\text { 1. Central Nucleus of Arts } \\
\text { and Cultural Heritage }\end{array}$ & $\begin{array}{c}\text { 2. Cultural } \\
\text { Industries }\end{array}$ & $\begin{array}{c}\text { 3. Creative } \\
\text { Industries }\end{array}$ & Total CCI \\
\hline 2007 & $Z(I)$ & $Z(I)$ & $Z(I)$ & $Z(I)$ \\
2008 & $6.754^{* *}$ & $8.552^{* *}$ & $11.557^{* *}$ & $10.971^{* *}$ \\
2009 & $6.559^{* *}$ & $8.427^{* *}$ & $11.611^{* *}$ & $10.829^{* *}$ \\
2010 & $6.212^{* *}$ & $8.399^{* *}$ & $11.590^{* *}$ & $10.540^{* *}$ \\
2011 & $6.645^{* *}$ & $8.431^{* *}$ & $11.212^{* *}$ & $10.463^{* *}$ \\
2012 & $6.516^{* *}$ & $8.374^{* *}$ & $11.210^{* *}$ & $10.230^{* *}$ \\
2013 & $6.485^{* *}$ & $8.307^{* *}$ & $11.160^{* *}$ & $10.128^{* *}$ \\
2014 & $6.579^{* *}$ & $8.053^{* *}$ & $11.091^{* *}$ & $10.052^{* *}$ \\
2015 & $6.404^{* *}$ & $8.391^{* *}$ & $11.060^{* *}$ & $10.115^{* *}$ \\
2016 & $6.403^{* *}$ & $8.368^{* *}$ & $10.835^{* *}$ & $10.040^{* *}$ \\
2017 & $6.292^{* *}$ & $8.091^{* *}$ & $10.786^{* *}$ & $9.926^{* *}$ \\
\hline
\end{tabular}

Notes: $(* *)$ All results are significant at the 1\% level. Z(I) is Moran's standardized I. Inference is based on 9999 permutations. Results obtained through a first order contiguity weights matrix.

As a result, this statistic measures the influences of a change in a variable at a given time and place $i$ and moment in the past $(t-k)$ on its geographical environment in the present $(t)$. The results (Table 5) show there is non-contemporary spatial dependence, as the statistic $Z\left(I_{t}\right)$ gives positive and significant values. This confirms our hypothesis concerning the existence of spatial-temporal diffusion in the location and distribution of CCI in Spain, in the sense that spatial groupings are the result of accumulated concentration and activity diffusion processes between neighboring areas, which benefit from the advantages offered by the proximity of the geographical area. This has a time element, as the interaction of the agents in the past continues to have an effect in the present, evidencing the existence of dynamic agglomeration economies in the CCI sector.

Table 5. Spatial-temporal bivariate $I_{t}$ statistic of CCI by sectors of activity, 2007-2017.

\begin{tabular}{ccccc}
\hline & $\begin{array}{c}\text { 1. Central Nucleus of Arts } \\
\text { and Cultural Heritage }\end{array}$ & $\begin{array}{c}\text { 2. Cultural } \\
\text { Industries }\end{array}$ & $\begin{array}{c}\text { 3. Creative } \\
\text { Industries }\end{array}$ & Total CCI \\
\hline & $\mathrm{Z}\left(I_{t}\right)$ & $\mathrm{Z}\left(I_{t}\right)$ & $\mathrm{Z}\left(I_{t}\right)$ & $\mathrm{Z}\left(I_{t}\right)$ \\
\hline $2007-2008$ & $6.717^{* *}$ & $8.517^{* *}$ & $10.905^{* *}$ & $10.899^{* *}$ \\
$2008-2009$ & $6.352^{* *}$ & $8.410^{* *}$ & $10.737^{* *}$ & $10.683^{* *}$ \\
$2009-2010$ & $6.496^{* *}$ & $8.432^{* *}$ & $11.068^{* *}$ & $10.506^{* *}$ \\
$2010-2011$ & $6.608^{* *}$ & $8.417^{* *}$ & $11.009^{* *}$ & $10.362^{* *}$ \\
$2011-2012$ & $6.540^{* *}$ & $8.346^{* *}$ & $10.874^{* *}$ & $10.201^{* *}$ \\
$2012-2013$ & $6.564^{* *}$ & $8.199^{* *}$ & $10.655^{* *}$ & $10.093^{* *}$ \\
$2013-2014$ & $6.502^{* *}$ & $8.245^{* *}$ & $10.618^{* *}$ & $10.086^{* *}$ \\
$2014-2015$ & $6.479^{* *}$ & $8.385^{* *}$ & $10.688^{* *}$ & $10.083^{* *}$ \\
$2015-2016$ & $6.339^{* *}$ & $8.237^{* *}$ & $10.676^{* *}$ & $9.978^{* *}$ \\
$2016-2017$ & $6.300^{* *}$ & $8.082^{* *}$ & $10.576^{* *}$ & $9.863^{* *}$ \\
$2007-2017$ & $6.638^{* *}$ & $8.408^{* *}$ & $11.200^{* *}$ & $10.412^{* *}$ \\
\hline
\end{tabular}

Notes: $\left(^{* *}\right)$ All results are significant at the $1 \%$ level. $\mathrm{Z}\left(I_{t}\right)$ is spatial-temporal standardized statistic. Inference is based on 9999 permutations. Results obtained through a first order contiguity weights matrix.

The results of global positive spatial autocorrelation need to be refined, and a distinction must be drawn between spatial groupings of high values and low values, respectively. With this aim in mind, the $I_{i}$ index of local spatial autocorrelation allows us to pinpoint significant clusters through the Moran scatterplot (Figure 3) and LISA maps (Figure 4). Many districts, on this occasion from a local spatial perspective, are characterized by positive spatial autocorrelation (most districts are found in the $\mathrm{HH}$ (high high) or LL (low low) quadrant), whereas only a small percentage of districts are characterized by negative spatial autocorrelation (HL (high low) or LH (low high) quadrants), thus confirming the same result as obtained when adopting a global perspective. The specific types of spatial autocorrelation are 
represented by various colors: red for the $\mathrm{HH}$ association, blue for the LL association, azure for LH, and finally pink for HL.
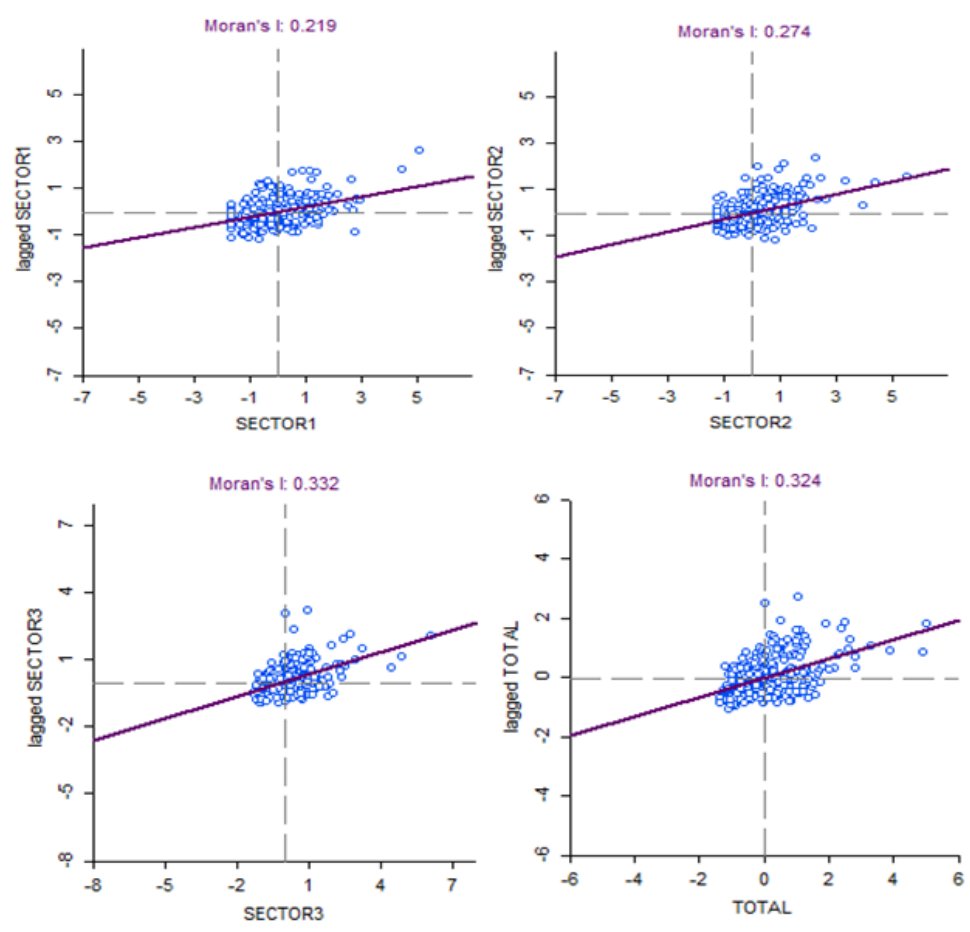

Figure 3. Moran Scatterplot of CCI (firms per capita) in Spanish districts, 2017.

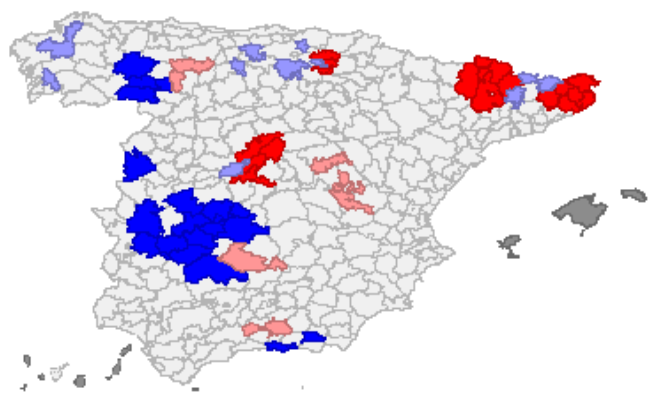

(a)

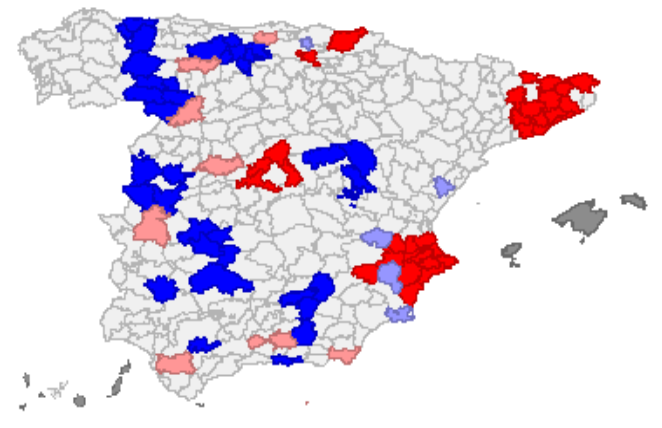

(c)

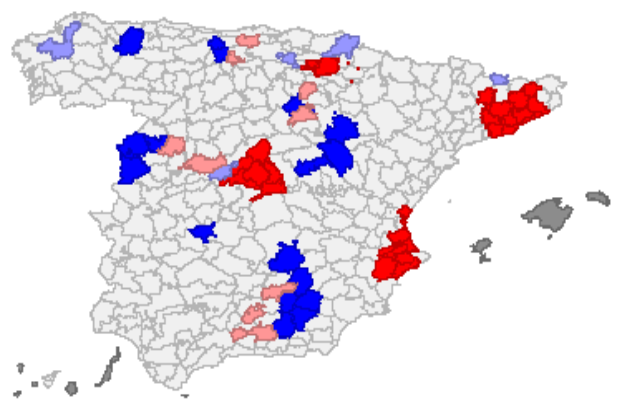

(b)

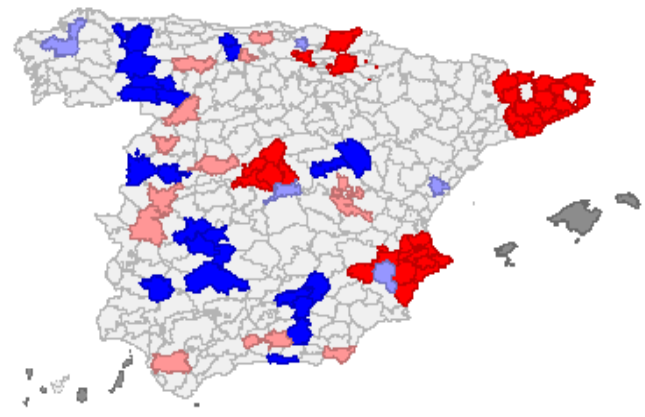

(d)

Figure 4. LISA map of spatial clusters of CCI in Spanish districts, 2017. (a) Central nucleus of arts and cultural heritage. (b) Cultural industries. (c) Creative industries. (d) Total CCI. 
Districts whose number of CCI firms is above the national average and greater than the mean of neighboring districts $(\mathrm{HH})$ tend to group spatially; in other words, they evidence a clear agglomeration pattern. These districts form the principal creative clusters that have a high number of CCI and show significant spatial interdependence. They are mainly located in areas of the Madrid region, Barcelona and North Catalonia, the Basque Country, and the province of Alicante and surrounding areas. Due to territorial interaction and spatial dissemination, $\mathrm{CCI}$ in turn form creative groupings in suburban areas, where territorial continuity appears as a driving force as, despite CCI being located in central nuclei, corridors of creative activity emerge, particularly in metropolitan regions and urban areas. In turn, many spatial clusters of empty areas (over 50\%) can be identified. These are characteristic due to their low values and some tend to be significantly grouped (LL). These clusters are mainly located in districts in the interior of the peninsula and are mostly geographically very far away from $\mathrm{HH}$ clusters, where the presence of CCI is scarce or non-existent, evidencing major territorial disparities in Spain in the area of CCI. Another kind of minority spatial grouping of creative activity are those shown on the map in the HL category, which have a high degree of participation in the CCI sector, but with little presence in their neighboring areas. They are therefore isolated areas with some emerging CCI activity, located in capitals in the south and west-vertical axis (Vía de la Plata), as well as in Basque provinces in the north. Finally, the LH category is districts with a low concentration in the CCI sector, but which are surrounded by areas with a large number of firms involved in this sector that are obviously located on the border of $\mathrm{HH}$ clusters, and which can be perceived as the first dissemination effect from them.

In sum, the distribution and location of spatial clusters generates a model displaying a sharp contrast between the center and the outlying areas of the peninsula. The large conglomerate in the region of Madrid acts as a center of gravity, the spatial-time progression of which coupled with dissemination and spread have triggered spillover effects, leading to the presence of CCI in areas that are interstitial to the central nucleus. Most of the remaining creative groupings are located in coastal areas, principally in the Mediterranean arc, with Cataluña as the central location node, although there is also a connection area between Alicante, Murcia, and Albacete. Large agglomerations of CCI emerge in certain districts in which the borders between metropolitan and non-metropolitan areas tend to disappear. This leads to the interesting perspective posited in the present research, namely disaggregation at the district level, with this being an intermediate spatial unit between provincial and municipal level. Nonetheless, the geographical configuration exhibits an extremely CCI concentrated distribution in Spanish districts, which also seems to show accumulated persistence over time. This leads us to consider technological gap models, therefore accentuating territorial disparities [7].

\section{Discussion and Conclusions}

This work presents an analysis of the structure, dynamics, and territorial distribution of the Spanish cultural and creative economy, from a spatial-temporal approach. The work aims to contribute to research dealing with location and agglomeration economy patterns in the cultural and creative sector, putting forward a spatial unit of analysis hitherto little used, districts, which enables spatial concentration and interaction processes to be explored in a more accurate manner than studies that use regions or provinces as the analysis unit. We first presented the structure of CCI by categories of activity in a time context and analyze business demography rates. We then calculated the Gini locational coefficients and applied spatial-temporal, global, and local spatial econometric techniques to study the agglomeration economies of the different groups of activities that make up the CCI sector.

CCI form a key part of the Spanish economy. Their weight in the economy as a whole is over $12 \%$ of all Spanish firms, a structure which is maintained over the period 2007-2017. In absolute terms, a clearly expansive trend in the number of firms can be seen, with the cultural and creative industries obtaining the lion's share of the total. The results of the descriptive analysis underline the high level of spatial concentration of CCI throughout Spain for the whole of the period analyzed, with over $80 \%$ of firms being located in only $10 \%$ of the main districts. In terms of groups of activities, creative industries 
are distributed in a more concentrated manner throughout the country, as are cultural industries, and relatively less the arts and heritage sector, which evidences greater dispersion in relative terms. Of course, these results and this concentration pattern had been observed before, but the use of districts as a spatial unit allowed us to disaggregate the analysis into territorial terms beyond provincial and regional limits, and to highlight the recurring trend of the creative sector towards territorial concentration, with dissemination and spatial spillovers in nearby areas. These knowledge-intensive activities require constant proximity and spatial interaction in order to form innovation processes, and are highly concentrated in the central nuclei of large urban areas and neighboring areas (such as Madrid and Barcelona), thus benefiting from the externalities of agglomeration economies.

The spatial distribution of CCI in Spanish districts presents a positive spatial autocorrelation both from a global and local standpoint for all the years in the study. This result evidences the existence of positive spatial externalities stemming from agglomerative processes in the CCI sector. With regard to the temporal dynamics of the spatial interaction of these activities over the study period, it can be seen how CCI locational patterns are characterized by non-contemporary spatial dependence, reflecting the existence of spatial-temporal dissemination and spread in the agglomeration economies of creative activities, referred to as dynamic agglomeration economies in the literature. In other words, there is significant temporal spread between areas, and the increase in the number of $\mathrm{CCI}$ in a given region has, over the period studied, led to an increase in the number of firms in this sector in its neighboring regions. Furthermore, spatial dynamics analysis shows that areas closest to creative clusters and urban nucleuses are those that benefit most from CCI growth due to spillover effects and spatial dependence, while in peripheral regions this phenomenon is not observed. This means that spatial disparities exist and are also reinforced over time, along the line of the consequences of technological gap models. Nevertheless, this argument needs to be confirmed by carrying out causal type studies, which is one of the future challenges facing this research.

In sum, the results to emerge using a more precise spatial scale, and from a spatial-temporal perspective, evidence substantial diversity in the cultural and creative performance of Spanish districts, whose locational pattern is concentrated in certain areas linked to the main metropolitan areas. These are activities that display strong spatial inertia, given the need to take advantage of spatial externalities and agglomeration economies. The location of creative clusters in Spanish districts evidences a sharp contrast between the center and outlying areas of the country, with a substantial number of Spanish districts being left to one side of the creative economy.

These empirical results may have policy implications, as we can ask ourselves whether the usual strategies of promoting the CCI sector beyond the main urban nodes could be successful. Indeed, it does not seem to be very useful to promote cultural and creative industries as engines of growth everywhere, because they have their own inertia to co-locate in major urban areas, to settle in districts with a previous consolidated production base in the matter, or at most possibly prove successful in neighboring areas. The boom of CCI runs the risk of all regions following very similar strategies in terms of being an attractive location for this sector, which has consequences on the accountability of the public resources invested in these purposes, because not all projects will enjoy the same success. Nevertheless, the poor performance of rural and peripheral regions can also be explained by a structural disadvantage, basically in the lack of skilled labor force, ICT facilities, as well as cultural amenities. Thus, any investment in improving these resources will yield great benefits. There is also the necessary institutional coordination between different territorial levels, as we show that the extension of the CCI sector over time exceeds the usual administrative limits of municipalities, provinces, and regions. Medium-sized cities and areas close to urban centers can benefit from the spatial externalities of the creative sector, and forming urban interregional cooperation networks might be an interesting strategy in this regard.

Certain challenges emerge from this work with regard to future research. These should include considering what influence the effects of interaction and spatial dynamic dependency from other sectors of the economy might have on the spatial distribution patterns of the CCI. Certain limitations 
in the results obtained, and which are mainly conditioned by the operational definition of the activities involved in this sector based on the availability of statistical data for the micro-spatial unit considered, should also be highlighted.

Author Contributions: I.B.-S.M. and L.C.H.-P. contributed equally to this work. All authors both read and approved the final manuscript.

Funding: This study was supported by the Regional Ministry of Education at the Regional Government of Castile and Leon (Spain) (project No. VA012G19).

Acknowledgments: The authors would like to thank participants at the XLIV International Conference on Regional Science, Valencia (2018), and the II Chinese-Spanish Seminar on Cultural Economics, Shanghai (2018), for comments and discussion on a preliminary version of the paper. The usual disclaimer applies.

Conflicts of Interest: The authors declare no conflict of interest.

\section{References}

1. United Nations Education, Scientifics and Cultural Organization. Creative Industries. Available online: http://www.unesco.org/new/es/culture/ (accessed on 25 July 2020).

2. Correa-Quezada, R.; Álvarez-García, J.; del Río-Rama, M.; Maldonado-Erazo, C. Role of Creative Industries as a Regional Growth Factor. Sustainability 2018, 10, 1649. [CrossRef]

3. Boix-Domenech, R.; Rausell-Kóster, P. The Economic Impact of the Creative Industry in the European Union. In Drones and the Creative Industry; Santamarina-Campos, V., Segarra-Oña, M., Eds.; Springer: Cham, Switzerland, 2018.

4. Lazzeretti, L.; Vecco, M. Creative Industries and Entrepreneurship: Paradigms in Transition from a Global Perspective; Edward Elgar Publishing: Cheltenham, UK, 2018.

5. Cellini, R.; Cuccia, T. Do behaviours in cultural markets affect economic resilience? An analysis of Italian regions. Eur. Plan. Stud. 2019, 27, 784-801. [CrossRef]

6. Montalto, V.; Moura, C.J.T.; Langedijk, S.; Saisana, M. Culture counts: An empirical approach to measure the cultural and creative vitality of European cities. Cities 2019, 89, 167-185. [CrossRef]

7. Boal, I.; Herrero, L.C. Reliability of Creative Composite Indicators with Territorial Specification in the EU. Sustainability 2020, 12, 3070. [CrossRef]

8. He, J.L.; Gebhardt, H. Space of creative industries: A case study of spatial characteristics of creative clusters in Shanghai. Eur. Plan. Stud. 2014, 22, 2351-2368. [CrossRef]

9. Evans, G. Creative cities, creative spaces and urban policy. Urban. Stud. 2009, 46, 1003-1040. [CrossRef]

10. Manitiu, D.; Pedrini, G. Urban smartness and sustainability in Europe. An ex ante assessment of environmental, social and cultural domains. Eur. Plan. Stud. 2016, 24, 1766-1787. [CrossRef]

11. Escalona-Orcao, A.I.; Escolano Utrilla, S.; Sáez-Pérez, L.A.; Sánchez-Valverde García, B. The location of creative clusters in non-metropolitan áreas: A methodological proposition. J. Rural. Stud. 2016, 45, 112-122. [CrossRef]

12. Mossig, I. Regional Employment Growth in the Cultural and Creative Industries in Germany 2003-2008. Eur. Plan. Stud. 2011, 19, 967-990. [CrossRef]

13. Cerisola, S. Creativity and local economic development: The role of synergy among different talents. Pap. Reg. Sci. 2016, 46, 637-660. [CrossRef]

14. Tao, J.; Ho, C.Y.; Luo, S.; Sheng, Y. Agglomeration economies in creative industries. Reg. Sci. Urban. Econ. 2019, 77, 141-154. [CrossRef]

15. Commonwealth of Australia, Department of Communications and the Arts (DCA). Creative Nation: Commonwealth Cultural Policy; DCA: Canberra, Australia, 1994.

16. Department of Culture, Media and Sport (DCMS). Creative Industries Mapping Document, 1st ed.; DCMS: London, UK, 1998.

17. Department of Culture, Media and Sport (DCMS). Creative Industries Mapping Document, 2nd ed.; DCMS: London, UK, 2001.

18. Department of Culture, Media and Sport (DCMS). Creative Industries Economic Estimates Satistical Bulletin; DCMS: London, UK, 2009. 
19. KEA. The Economy of Culture in Europe; European Commission Directorate-General for Education and Cultue: Brussels, Belgium, 2006.

20. United Nations Conference on Trade and Development. Creative Economy Report 2008; UNCTAD: Geneva, Switzerland; New York, NY, USA, 2008.

21. United Nations Conference on Trade and Development. Creative Economy Report 2010; UNCTAD: Geneva, Switzerland; New York, NY, USA, 2010.

22. Boix-Domenech, R.; Lazzeretti, L. Las industrias creativas en España: Una panorámica. Investig. Reg. 2012, 22, 181-2015.

23. Bertacchini, E.; Borrione, P. The geography of the Italian creative economy: The special role of the design and craft-based industries. Reg. Stud. 2013, 47, 135-147. [CrossRef]

24. Boix-Domenech, R.; Hervás-Oliver, J.L.; De Miguel Molina, B. Micro-geographies of creative industries clusters in Europe: From hot spots to assemblages. Pap. Reg. Sci. 2015, 94, 753-773. [CrossRef]

25. Arauzo, J.M.; Viladecans, E. Industrial Location at the Intra-metropolitan Level: The Role of Agglomeration Economies. Reg. Stud. 2009, 43, 545-558. [CrossRef]

26. Lee, B.K.; Sohn, S.Y. Disparities in exploitative and exploratory patenting performance across regions: Focusing on the roles of agglomeration externalities. Pap. Reg. Sci. 2019, 98, 241-263. [CrossRef]

27. Backman, M.; Nilson, P. The role of cultural heritage in attracting skilled individuals. J. Cult. Econ. 2018, 42, 111-138. [CrossRef]

28. Gong, H.; Hassink, R. Exploring the clustering of creative industries. Eur. Plan. Stud. 2017, 25, 583-600. [CrossRef]

29. Jofre-Monseny, J.; Marín-López, R.; Viladecans-Marsal, E. The determinants of localization and urbanization economies: Evidence from the location of new firms in Spain. J. Reg. Sci. 2014, 54, 313-337. [CrossRef]

30. Glaesser, E. The new economics of urban and regional growth. In The Oxford Handbook of Economic Geography; Clark, G., Feldman, M., Gertler, M., Eds.; Oxford University Press: Oxford, UK, 2000.

31. Benita, F. On the performance of creative industries: Evidence from Mexican metropolitan areas. Pap. Reg. Sci. 2019, 978, 825-842. [CrossRef]

32. Mellander, C.; Florida, R. The rise of skills: Human capital, the creative class, and regional development. In Handbook of Regional Science; Fischer, M., Nijkamp, P., Eds.; Springer: Berlín, Germany, 2018.

33. Andersson, Å.E.; Andersson, D.E.; Daghbashyan, Z.; Hårsman, B. Location and spatial clustering of artists. Reg. Sci. Urban. Econ. 2014, 47, 128-137. [CrossRef]

34. Markusen, A. Sticky places in slippery space: A typology of industrial districts. Econ. Geogr. 1996, 72, 293-313. [CrossRef]

35. Ženka, J.; Slach, O.; Ivan, I. Spatial patterns of knowledge-intensive business services in cities of various sizes, morphologies and economies. Sustainability 2020, 12, 1845. [CrossRef]

36. Lazzeretti, L.; Capone, F.; Boix, R. Reasons for clustering of creative industries in Italy and Spain. Eur. Plan. Stud. 2012, 20, 1243-1262. [CrossRef]

37. Brazanti, C. Creative Clusters and District Economies: Towards a Taxonomy to Interpret the Phenomenon. Eur. Plan. Stud. 2015, 23, 1401-1418. [CrossRef]

38. Scott, A. Creative cities: Conceptual issues and policy questions. J. Urban. Aff. 2006, 28, 1-17. [CrossRef]

39. Bereitschaft, B. Neighbourhood Change among Creative-Cultural Districts in Mid-Sized US Metropolitan Areas, 200-210. Reg. Stud. Reg. Sci. 2014, 1, 158-183.

40. Lee, N. The creative industries and urban economic growth in the UK. Environ. Plan. A 2014, 46, 455-470. [CrossRef]

41. Hong, J.; Yu, W.; Guo, X.; Zhao, D. Creative industries agglomeration, regional innovation and productivity growht in China. Chin. Geogr. Sci. 2014, 24, 258-268. [CrossRef]

42. Casares, P.; Coto-Millán, P.; Inglada López de Sabando, V. Talento, tecnología y desarrollo económico en las provincias españolas. Investig. Reg. 2012, 22, 57-80.

43. Méndez, R.; Sánchez Moral, S. Spanish cities in the knowledge economy: Theoretical debates and empirical evidences. Eur. Urban. Reg. Stud. 2011, 18, 136-155. [CrossRef]

44. Méndez, R.; Michelini, J.J.; Prada, J.; Tébar, J. Economía creativa y desarrollo urbano en España: Una aproximación a sus lógicas espaciales. EURE 2012, 38, 5-32. [CrossRef]

45. Coll-Martínez, E.; Moreno-Monroy, A.I.; Arauzo-Carod, J.M. Agglomeration of creative industries: An intra-metropolitan analysis for Barcelona. Pap. Reg. Sci. 2019, 98, 409-431. [CrossRef] 
46. Cliff, A.; Ord, D. Spatial Processes: Models and Applications; Pion: London, UK, 1981.

47. Moreno, R.; Vayá, E. Técnicas Econométricas Para el Tratamiento de Datos Espaciales: La Econometría Espacial; Edicions Universitat de Barcelona: Barcelona, Spain, 2000.

48. Chasco, C.; López, F. Is spatial dependence an instantaneous effect? Some evidence in economic series of Spanish provinces. Estadística Española 2008, 50, 101-118.

49. Anselin, L. Local indicators of spatial association-LISA. Geogr. Anal. 1995, 27, 93-115. [CrossRef]

50. Fariñas, J.C.; Huergo, E. Demografía Empresarial en España: Tendencias y Regularidades; FEDEA: Madrid, Spain, 2015; No. 2015/24.

51. García, M.I.; Fernández, Y.; Zofío, J.L. The economic dimensión of the culture and leisure industry in Spain: National, sectoral and regional analysis. J. Cult. Econ. 2003, 27, 9-30. [CrossRef]

52. Boal, I.; Herrero, L.C. Where are the artists? Analysing economies of agglomeration in Castile and León, Spain. Pap. Reg. Sci. 2018, 97, 995-1016. [CrossRef]

53. Anselin, L. Exploring Spatial Data with GeoDa: A Work Book; University of Illinois: Urbana, IL, USA, 2005.

(C) 2020 by the authors. Licensee MDPI, Basel, Switzerland. This article is an open access article distributed under the terms and conditions of the Creative Commons Attribution (CC BY) license (http://creativecommons.org/licenses/by/4.0/). 